\title{
A priori sensitivity analysis for densification GPS networks and their capacities of crustal deformation monitoring: a real GPS network application
}

\author{
P. Küreç and H. Konak \\ Department of Surveying Engineering, Kocaeli, Turkey \\ Correspondence to: P. Küreç (pkurec80@yahoo.com)
}

Received: 2 August 2012 - Published in Nat. Hazards Earth Syst. Sci. Discuss.: -

Revised: 9 July 2013 - Accepted: 26 March 2014 - Published: 23 May 2014

\begin{abstract}
The main purpose of this study is to investigate the possibilities of monitoring crustal movement, during collective evaluation of first- and second-order GPS densification networks. The new criteria, which are independent from the network datum, are widely used for the evaluation and quality processing of geodetic networks. In this study, the values of detectable minimum displacement for a real GPS network are investigated as well as how sensitivity levels are affected by additional datum conditions, which are added to the adjustment model.
\end{abstract}

\section{Introduction}

In a comparison of different periods or campaigns related to a geodetic network, the magnitude of the undetectable systematic errors in the coordinate differences gives us important information about the sensitivity level of the geodetic network. The reliability analysis of the geodetic networks was firstly introduced by Baarda (1968) with his famous study about data snooping. Nowadays, this approach, which is quite popular in the field of geodesy science, has been discussed together with robustness and sensitivity analysis. For example, Baarda's traditional reliability analysis has been augmented with strain analysis in a doctoral thesis of Berber (2006). The minimum detectable displacement value is called the sensitivity of the deformation model (Hsu and Hsiao, 2002; Küreç, 2010). Recently, research on robustness and sensitivity levels of geodetic networks has gained more importance. Concentrating in the last few years the studies are carried out together with strain models (Hsu et al., 2008; Han et al., 2011; Even-Tzur, 2006, 2010). Even-Tzur (2010) suggested that the sensitivity levels of geodetic networks could be able to improve by using an extended Helmert transformation model representing the strain model. On the other hand, Han et al. (2011) applied the sensitivity analysis techniques for the network strain and stress analysis in their study (Han et al., 2011).

In this study, a mixed approach is proposed for the analysis of sensitivity. This approach is a synthesis of three different analysis techniques, which are called a priori sensitivity analysis, external reliability analysis and the effects of extended datum condition on the sensitivity levels. The suggested approach is tested in a real GPS densification (GPS-D) network, and then the adequacy of obtained a priori sensitivity values are reviewed together with reliability requirements. In addition, according to the extended datum condition, behaviours of sensitivity levels are examined comparatively.

\section{A priori sensitivity analysis technique}

The observations in geodetic networks are evaluated collectively with the Gauss-Markoff Model using the least squares method (Wolf, 1975; Boljen, 1993; Koch, 2004). The least squares estimation of the unknown parameters is obtained as

$\hat{\boldsymbol{x}}=\left(\mathbf{A}^{T} \mathbf{P A}\right)^{+} \mathbf{A}^{T} \mathbf{P} \boldsymbol{l}=\mathbf{N}^{+} \mathbf{A}^{T} \mathbf{P} \boldsymbol{l}$,

where $\mathbf{A}$ is the design matrix, $\mathbf{P}$ is the weight matrix and $\boldsymbol{l}$ is the observation vector. The difference vector $(\boldsymbol{d})$ for the adjusted coordinates $\left(\hat{\boldsymbol{x}}_{i}\right)$ in $t_{1}$ and $t_{2}$ 
epochs can be described as

$\boldsymbol{d}=\hat{\boldsymbol{x}}_{2}-\hat{\boldsymbol{x}}_{1}$.

The cofactor matrix of the difference vector is obtained by using the propagation law of variance-covariance for Eqs. (1) and (2).

$\mathbf{Q}_{d d}=\left(\mathbf{A}_{1}^{T} \mathbf{P}_{1} \mathbf{A}_{1}\right)^{+}+\left(\mathbf{A}_{2}^{T} \mathbf{P}_{2} \mathbf{A}_{2}\right)^{+}=\mathbf{Q}_{x_{1} x_{1}}+\mathbf{Q}_{x_{2} x_{2}}$

The global congruence test value $(T)$ for analysis of the deformation measurements can be derived with the following equation:

$$
\left(T=\frac{\boldsymbol{d}^{T} \mathbf{Q}_{d d}^{+} \boldsymbol{d}}{s_{0}^{2} h}\right),
$$

where $h$ is rank of a deformation model and $s_{0}^{2}$ is a priori variance of a deformation model (Pelzer, 1971; Öztürk and Şerbetçi, 1992; Niemeier, 2002; Eshagh, 2009). If $T>F_{h, f, 1-\alpha}$ ( $f$ is the degree of freedom for a deformation model and $(1-\alpha)$ is a confidence level), it is assumed that the network points include significant displacements.

The least squares estimation values of obtained unknown parameters $(\boldsymbol{x})$ as a result of the evaluation at any period of a geodetic network depend upon the possible errors revealed in observation vector $(\boldsymbol{l})$. In the comparison process of a network evaluated at different epochs, it is not proposed that the datum, a priori variance of a unit weight and approximate coordinates of the network are to be changed (Aksoy et al., 1995).

If there is no displacement at the network points, it is assumed that the observations vector includes randomly distributed errors. In this case, deformation model can be reformulated as the differential change of randomly distributed observations $(\delta \boldsymbol{l})$.

$\boldsymbol{d}=\mathbf{N}^{+} \mathbf{A}^{T} \mathbf{P} \delta \boldsymbol{l}$

According to the propagation law of errors, the cofactor matrix $\left(\mathbf{Q}_{d d}\right)$ can be written as

$\mathbf{Q}_{d d}=\mathbf{N}^{+}$.

If there is any displacement in the networks points, one may assume that the vector $(\boldsymbol{d})$ has a normal distribution with mean $(\overline{\boldsymbol{d}})$ and variance $\left(\boldsymbol{\Sigma}_{d}\right)$. In this case, the quadratic form $\boldsymbol{d}^{T} \boldsymbol{\Sigma}_{d d}^{+} \boldsymbol{d}$ has a chi-squared distribution with degree of freedom $(u)$ and non-centrality parameter $\xi_{0}^{2}=\overline{\boldsymbol{d}}^{T} \boldsymbol{\Sigma}_{d d}^{+} \overline{\boldsymbol{d}}$ (Hsu and Hsiao, 2002; Koch, 2004; Even-Tzur, 2010).

The Model Hypothesis test can be written as

$$
\begin{aligned}
& H_{0}: \xi^{2} \leq \delta_{0}^{2} \\
& H_{1}: \xi^{2}>\delta_{0}^{2},
\end{aligned}
$$

where $\delta_{0}^{2}$ is a threshold value of a non-centrality parameter, $H_{0}$ is the null hypothesis and $H_{1}$ is the alternative hypothesis.
The null hypothesis is accepted if

$\xi^{2}=\frac{\overline{\boldsymbol{d}}^{T} \mathbf{P}_{d d} \overline{\boldsymbol{d}}}{\sigma^{2}} \leq \delta_{0}^{2}$.

In other words, the vector $(\boldsymbol{d})$ is a random vector and should be considered as the marginal random error vector that contains no information statistically (Hsu and Hsiao, 2002). When Eq. (8) is resolved, the minimum detectable displacement value is obtained as a sensitivity level. The quadratic form $\overline{\boldsymbol{d}}^{T} \mathbf{P}_{d d} \overline{\boldsymbol{d}}$ is decomposed as

$\overline{\boldsymbol{d}}^{T} \mathbf{P}_{d d} \overline{\boldsymbol{d}}=\overline{\boldsymbol{d}}^{T} \boldsymbol{S} \Lambda \mathrm{S}^{T} \overline{\boldsymbol{d}}$.

This equation can be reconstructed as a function of eigenvalues

$\overline{\boldsymbol{d}}^{T} \mathbf{P}_{d d} \overline{\boldsymbol{d}}=\|d\| \sum_{i=1}^{u} \lambda_{i}$.

Equation (10) can be derived as follows:

$\|d\|^{2}=\frac{\delta_{0}^{2} \sigma^{2}}{\sum_{i=1}^{u} \lambda_{i}}$

where $\sigma^{2}$ is the theoretical variance of a unit weight and $\lambda_{i}$ is an eigenvalue for $i$ th network point. If Eq. (11) is written for the largest eigenvalue $\left(\lambda_{\max }\right)$ of the matrix $(\mathbf{N})$, the magnitude of marginal random-error vector is

$\|d\|_{\min }=\frac{\delta_{0} \sigma}{\sqrt{\lambda_{\max }}}$,

where $\|d\|_{\min }$ is called the best sensitivity level or the minimum detectable displacement value. Similarly, if Eq. (11) is rewritten for the smallest eigenvalue $\left(\lambda_{\min }\right)$, the worst capability of the network is

$\|d\|_{\max }=\frac{\delta_{0} \sigma}{\sqrt{\lambda_{\min }}}$.

In practical applications, the local sensitivity criteria are quite useful. A global sensitivity criterion for the geodetic networks could be estimated by simple averaging all local sensitivities (Hsu and Hsiao, 2002; Hsu et al., 2008).

Using Eq. (2), the displacement vector $(\boldsymbol{d})$ is written for 3-D GPS networks as

$\left[\begin{array}{c}\boldsymbol{d}_{x_{1}} \\ \boldsymbol{d}_{x_{2}} \\ \cdot \\ \boldsymbol{d}_{x_{u}}\end{array}\right]=\left[\begin{array}{cccc}\mathbf{N}_{11} & \mathbf{N}_{12} & \cdot & \mathbf{N}_{1 u} \\ \mathbf{N}_{21} & \mathbf{N}_{22} & \cdot & \mathbf{N}_{2 u} \\ \cdot & \cdot & \cdot & \cdot \\ \mathbf{N}_{u 1} & \mathbf{N}_{u 2} & \cdot & \mathbf{N}_{u u}\end{array}\right]^{+} \cdot\left[\begin{array}{c}\boldsymbol{n}_{1} \\ \boldsymbol{n}_{2} \\ \cdot \\ \boldsymbol{n}_{u}\end{array}\right]$.

For a single GPS station, this equation can be reconstructed as

$\boldsymbol{d}_{i}=\left[\begin{array}{llll}\mathbf{N}_{11} & \mathbf{N}_{12} & \ldots & \mathbf{N}_{1 u}\end{array}\right]^{+} \cdot\left[\begin{array}{c}\boldsymbol{n}_{1} \\ \boldsymbol{n}_{2} \\ \vdots \\ \boldsymbol{n}_{u}\end{array}\right]=\ddot{\mathbf{N}}_{i} \mathbf{A}^{T} \mathbf{P} l$ 
From Eq. (15), the law of variance-covariance propagation gives us the cofactor matrix of $\left(\boldsymbol{d}_{i}\right)$ as

$$
\begin{aligned}
\mathbf{Q}_{d_{i} d_{i}} & =\ddot{\mathbf{N}}_{i} \mathbf{A}^{T} \mathbf{P} \mathbf{Q}_{l l} \mathbf{P A} \ddot{\mathbf{N}}_{i}^{T} \\
\mathbf{Q}_{d_{i} d_{i}} & =\ddot{\mathbf{N}}_{i} \mathbf{N} \ddot{\mathbf{N}}_{i}^{T}
\end{aligned}
$$

or the weight matrix of $\left(\mathbf{d}_{i}\right)$ as

$\mathbf{P}_{d_{i}}=\mathbf{Q}_{d_{i} d_{i}}^{-1}$.

By analysing the eigenvalues of the weight matrix $\left(\mathbf{P}_{d_{i}}\right)$ for each network point, the minimum detectable displacement values, namely the sensitivity levels, are estimated (Hsu and Hsiao, 2002; Küreç, 2010).

\subsection{Sensitivity analysis of geodetic densification networks}

The sensitivity levels for the geodetic network points are individually computed (Küreç, 2010). The computed steps are summarized as follows:

(a) For each station point, weight matrix ( $\left.\mathbf{N}_{i i}\right)$ is computed.

$$
\begin{aligned}
\mathbf{N}_{i i} & =\left(\ddot{\mathbf{N}}_{i} \mathbf{N} \ddot{\mathbf{N}}_{i}^{T}\right)^{-1}=\mathbf{P}_{d_{i}}^{-1} \\
\mathbf{N}_{i i} & =\left[\begin{array}{lll}
\boldsymbol{n}_{11} & \boldsymbol{n}_{12} & \boldsymbol{n}_{13} \\
\boldsymbol{n}_{21} & \boldsymbol{n}_{22} & \boldsymbol{n}_{23} \\
\boldsymbol{n}_{31} & \boldsymbol{n}_{32} & \boldsymbol{n}_{33}
\end{array}\right]_{i}
\end{aligned}
$$

(b) Eigenvalues and eigenvectors are computed for each $\left(\mathbf{N}_{i i}\right)$.

(c) The direction cosines are computed from the eigenvector matrix (S) for each unknown coordinate. The values give us information about the directions of azimuth and zenith angles.

(d) The direction cosines are transformed into a local topocentric coordinate system $(n, e, w)$.

$\left[\begin{array}{l}n \\ e \\ w\end{array}\right]=\left[\begin{array}{ccc}-\sin \phi \cos \lambda & -\sin \phi \sin \lambda & \cos \phi \\ -\sin \phi & \cos \lambda & 0 \\ \cos \phi \cos \lambda & \cos \phi \sin \lambda & \sin \phi\end{array}\right] \cdot\left[\begin{array}{c}\Delta X \\ \Delta Y \\ \Delta Z\end{array}\right]$

Instead of vector components, $\left[\begin{array}{ccc}\Delta X & \Delta Y & \Delta Z\end{array}\right]^{T}$ are replaced by the direction cosines, namely principal stress elements.

$\left[\begin{array}{l}n \\ e \\ w\end{array}\right]=\left[\begin{array}{ccc}-\sin \phi \cos \lambda & -\sin \phi \sin \lambda & \cos \phi \\ -\sin \phi & \cos \lambda & 0 \\ \cos \phi \cos \lambda & \cos \phi \sin \lambda & \sin \phi\end{array}\right] \cdot\left[\begin{array}{c}\cos \alpha \\ \cos \beta \\ \cos \gamma\end{array}\right]$

where $\varphi$ and $\lambda$ are ellipsoidal coordinates. (e) The azimuth and zenith angles of eigenvectors are computed thus:

$\alpha=\tan ^{-1} \frac{e}{n}$,

$\varsigma=90^{\circ}-\tan ^{-1} \frac{w}{\sqrt{e^{2}+n^{2}}}$.

(f) By use of the azimuth and zenith angles, the displacements elements are determined as

$\tilde{e}=\|d\|_{\min } \sin \varsigma \sin \alpha ; \tilde{n}=\|d\|_{\max } \sin \varsigma \cos \alpha$,

where $\tilde{e}$ is east and $\tilde{n}$ is north components of marginal displacement vector.

(g) The local sensitivity levels obtained for every network point are indicated.

(h) The external reliability values are computed for every geodetic network point.

(i) The observation plan is reviewed once more.

(j) The quantitative and graphical results are interpreted collectively.

\subsection{The external reliability criteria}

"During the total evaluation process of the observations, the estimated residuals belonging to each observation are obtained with respect to the random errors, mentioned on the estimated values determined depending upon the reliability rate of observations" (Konak et al., 2005). The reliability of a geodetic network can be described as the undetectable gross errors or influences of the maximum undetectable blunders $\left(\boldsymbol{\Delta}_{0 i}\right)$ on the coordinate unknowns (Kuang, 1991; Konak, 1995). Equation (1) is modified as

$\Delta \boldsymbol{x}=\left(\mathbf{A}^{T} \mathbf{P A}\right)^{-1} \mathbf{A}^{T} \mathbf{P} e_{i} \Delta_{0 i}$.

Then a reliability criterion can be determined as independent from datum definition, namely the external reliability.

$$
\begin{aligned}
& \left\|\delta_{0 i}\right\|^{2}=\Delta x^{T} \sum_{x x}^{-1} \Delta x \\
& =\frac{1}{m_{0}^{2}} \Delta_{0 i}^{2} \boldsymbol{e}_{i}^{T} \mathbf{P} \mathbf{A} \mathbf{Q}_{x x} \mathbf{Q}_{x x}^{-1} \mathbf{Q}_{x x} \mathbf{A}^{T} \mathbf{P} e_{i},
\end{aligned}
$$

where $\Delta_{0 i}$ is the internal reliability and $m_{0}^{2}$ is the a posteriori value of the experimental variance (Niemeier, 2002; Öztürk and Şerbetçi, 1992).

This equation is designed as

$$
\begin{aligned}
& \left\|\delta_{0 i}\right\|^{2}=\frac{1}{m_{0}^{2}} \frac{\delta_{0}^{2} m_{0}^{2}}{\boldsymbol{e}_{i}^{T} \mathbf{P} \mathbf{Q}_{v v} \mathbf{P} \boldsymbol{e}_{i}} \boldsymbol{e}_{i}^{T} \mathbf{P A} \mathbf{Q}_{x x} \mathbf{A}^{T} \mathbf{P} \boldsymbol{e}_{i} \\
& =\delta_{0}^{2} \frac{\boldsymbol{e}_{i}^{T} \mathbf{P}\left(\mathbf{Q}_{l l}-\mathbf{Q}_{v v}\right) \mathbf{P} \boldsymbol{e}_{i}}{\boldsymbol{e}_{i}^{T} \mathbf{P} \mathbf{Q}_{v v} \mathbf{P} \boldsymbol{e}_{i}},
\end{aligned}
$$


Table 1. The critical values of reliability levels in geodetic networks (for $\delta_{0}^{2}=10.903$ ). Significant level $\alpha_{0}=0.05$, the power of the test $\gamma_{0}=\% 80$ and degree of freedom $h=3$.

\begin{tabular}{llll}
\hline $\begin{array}{l}\text { Redundancy } \\
r_{i}=\left(\mathbf{Q}_{v v} \mathbf{P}_{i}\right)_{i i}\end{array}$ & $\begin{array}{l}\text { Internal reliability } \\
k=\Delta_{o i} / m_{i}\end{array}$ & $\begin{array}{l}\text { External reliability } \\
\delta_{0 i}\end{array}$ & Controllability rate \\
\hline $0 \leq r_{i}<0.01$ & $30 \leq k<\infty$ & $25 \leq \delta_{0 i}<\infty$ & Uncontrollable \\
$0.01 \leq r_{i}<0.10$ & $10 \leq k<30$ & $15 \leq \delta_{0 i}<25$ & Weak \\
$0.10 \leq r_{i}<0.30$ & $6 \leq k<10$ & $8 \leq \delta_{0 i}<15$ & Sufficient \\
$0.30 \leq r_{i}<1.00$ & $0 \leq k<6$ & $0 \leq \delta_{0 i}<8$ & Excellent \\
\hline
\end{tabular}

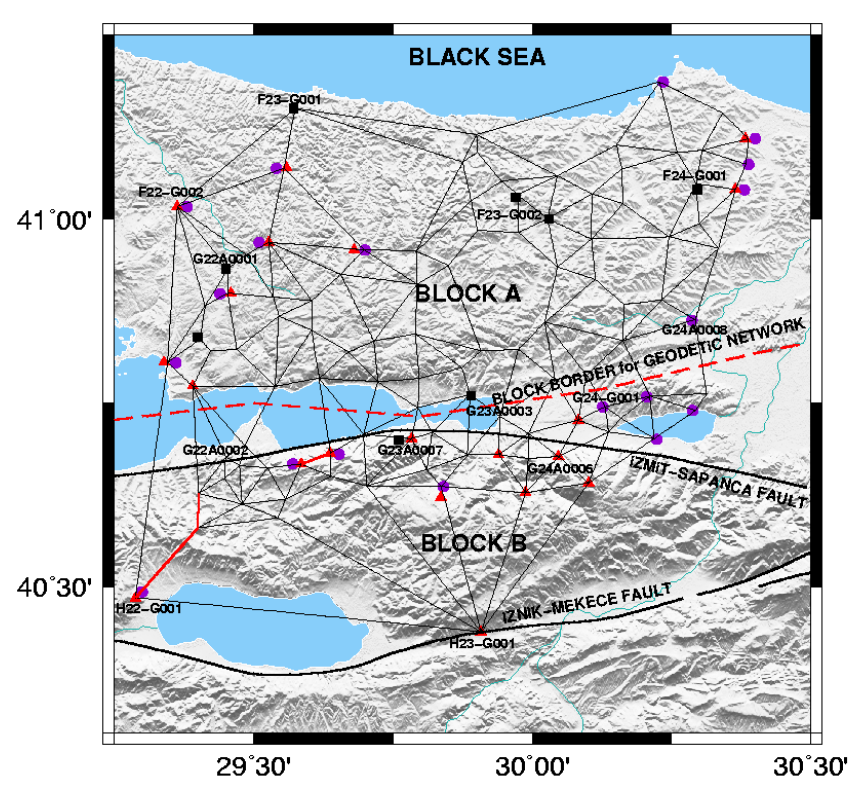

Figure 1. Observation plan of the Kocaeli GPS-D network ((o): moving points according to results of 3-D Helmert transformation $\left(m_{0}=2.20 \mathrm{~cm}\right) ;(\triangle)$ : moving points according to results of extended Helmert transformation $\left(m_{0}=2.54 \mathrm{~cm}\right)$; $(\boldsymbol{\square})$ : fixed points according to the result of Helmert transformation. The red base lines show external reliability values higher than 8 .).

where $\boldsymbol{e}_{i}$ is a design vector for $i$ th GPS station, $\mathbf{Q}_{x x}$ is the cofactor matrix of the unknown parameters, $\mathbf{Q}_{l l}$ is the cofactor matrix of observations and $\mathbf{Q}_{v v}$ is the cofactor matrix of corrections.

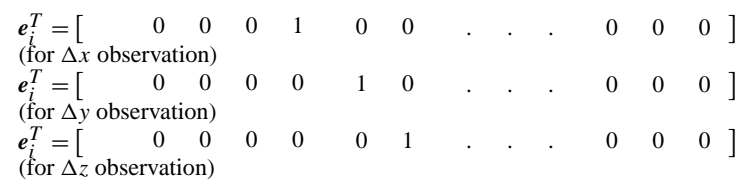

The controllability levels and precision of observations are important indicators of geodetic network quality. "Geodetic Networks, in order to perform the duty expected from them, are designed to fit into the most suitable structure in terms of observation plan, precision and reliability." As a result of this, the detectable capacity of the network's deformations depends upon the quality of the network (Konak et al., 2005; Öztürk and Şerbetçi, 1992). In a sufficiently designed geode- tic network, external reliability levels $\left(\delta_{0 i}\right)$ remain between 6 and 10 units (Table 1).

For this aim, an analytical approximation for the optimal observation plan and optimal dispersion of their reliabilities, namely second-order design problems, should be purposed. However, the primary subject of the study is not the development of any second-order design (SOD). For more details, the literature (Cross, 1985; Kuang, 1991; Konak, 1995; Yetkin and İnal, 2011) should be viewed. A standard SOD process is summarized by the following.

(a) Specify a set of possible observations (or configuration) and their precision and reliability criteria.

(b) The second-order design problems are solved and observation weights $\left(p_{i}\right)$ are obtained. If $p_{i}<0$, the $i$ th observation is removed from the observation plan and this solution method is iterated (for example, a weight optimization based on the least squares solution) (Schmitt, 1985).

(c) Discard any observations whose required variance is large because they will not significantly contribute to the final precision and reliability of the network.

In last step, if external reliability values $\left(\left|\delta_{o i}\right|\right) \leq 6$, the $i$ th observation is discarded and then the reliability dispersion of network is checked once more. If the specified criteria are satisfied, the process of SOD is ended.

\section{A sensitivity analysis strategy for the Kocaeli IZDO- GAP GPS densification network}

In this paper, a scientific and engineering purposed network (Kocaeli GPS-D network) is considered as a sample GPS network. The network is located west of the North Anatolian Fault Zone (NAFZ) called as the Izmit-Sapanca Fault in Turkey. It is situated approximately from $40^{\circ} 30^{\prime} \mathrm{N}$ to $41^{\circ} 00^{\prime} \mathrm{N}$ latitude and from $29^{\circ} 00^{\prime} \mathrm{E}$ to $30^{\circ} 30^{\prime} \mathrm{E}$ longitude (Fig. 1).

"As known, the Anatolian plate squeezed by the Arabian plate is escaping towards the west along the North and Eastern Anatolian Faults. As a result of this the Anatolian plate expands and rotates anticlockwise in the west" 
Table 2. Reliability levels in the Kocaeli GPS-D network.

\begin{tabular}{|c|c|c|c|c|c|c|}
\hline & \multicolumn{2}{|c|}{ Redundancy } & \multicolumn{2}{|c|}{ Internal reliability } & \multicolumn{2}{|c|}{ External reliability } \\
\hline & $\begin{array}{c}0.10 \leq r_{i}<0.30 \\
\text { Sufficient }\end{array}$ & $\begin{array}{c}0.30 \leq r_{i}<1.00 \\
\text { Excellent }\end{array}$ & $\begin{array}{l}6 \leq k<10 \\
\text { Sufficient }\end{array}$ & $\begin{array}{l}0 \leq k<6 \\
\text { Excellent }\end{array}$ & $\begin{array}{c}8 \leq \delta_{0 i}<15 \\
\text { Sufficient }\end{array}$ & $\begin{array}{c}0 \leq \delta_{0 i}<8 \\
\text { Excellent }\end{array}$ \\
\hline $\begin{array}{l}\stackrel{\mathscr{\Xi}}{\Xi} \\
: \\
\tilde{\Xi} \\
\tilde{\Xi}\end{array}$ & $\begin{array}{c}19-16 \\
17-19 \\
24-27 \\
27-33 \\
7-9 \\
103-38 \\
8-2 \\
93-96 \\
- \\
3-4 \\
71-67 \\
87-52 \\
- \\
- \\
-\end{array}$ & 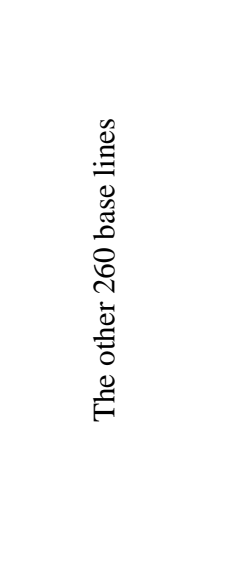 & $\begin{array}{c}19-16 \\
17-19 \\
24-27 \\
27-33 \\
7-9 \\
103-38 \\
- \\
- \\
39-38 \\
- \\
- \\
- \\
28-49 \\
57-56 \\
99-95\end{array}$ & 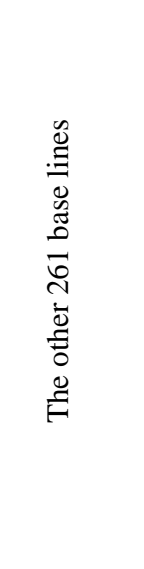 & $\begin{array}{c}19-16 \\
17-19 \\
24-27 \\
27-33 \\
7-9 \\
103-38 \\
8-2 \\
93-96 \\
39-38 \\
- \\
- \\
- \\
- \\
- \\
-\end{array}$ & 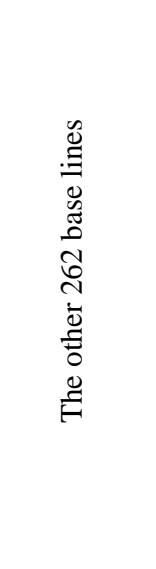 \\
\hline
\end{tabular}

(İnce et al., 2001). In 1999, two earthquakes of 7.4 and 7.2 magnitude occurred in the study area. Due to the geodynamic nature of the region, the study area is expected to move approximately $1-2 \mathrm{~cm}$ per year. Therefore, the the Kocaeli GPS-D network has been established to monitor crustal movement effects and to control for natural gas pipelines since 2009. The aim of the paper is to focus on the a priori sensitivity analysis for the network points. In the sample GPS network, there are in total 271 baseline vectors ranging approximately from 3 to $15 \mathrm{~km}$. This network has 106 GPS points. In this network, 83 GPS points selected from TUTGA (Turkish National Fundamental GPS Network), AGA and SGA (first- and second-order densification GPS network) are designed as common control points (IZDOGAP, 2011).

The observation plan of the Kocaeli GPS-D network is created by using a weight optimization based on the least squares solution. According to the result of the optimization operation, 271 GPS base lines are chosen for use in the Kocaeli GPS-D network with 106 points. The GPS observations of the Kocaeli GPS-D network are evaluated together in the Gauss-Markov model as the indirect measurements and then the reliability values of all observations at the first epoch $\left(t_{0}=2009\right)$ are computed. Then, the dispersion of observations and their reliability values are checked. When the observations of the network are analysed according to the criteria of reliability, controllability rate of approximately 10 GPS base lines are qualified as "sufficient" and the others are also "excellent" (Table 2). Some of the sufficient base lines are located in the inner zone of the network and the others are also in the polygonal-shaped loops (Fig. 1).

The Kocaeli GPS-D network is dealt with in the form of two mean blocks according to the nature of their geodynamic. The network is divided by the NAFZ. Due to geo- logical and geodynamic natures of NAFZ, the south of the Kocaeli GPS-D network has a different network's barycentre (shift) and rotation. Furthermore, the south part of the network is regarded as a separate block (active block; Block B).

Using the free network adjustment method, the network is evaluated in the datum of the common network points which are located in the north of NAFZ (block A). Then the free adjusted coordinates set of block $B$ is transformed into a new datum belonging to a different barycentre by using an extended Helmert transformation model (Fig. 1). This evaluation process is summarized as follows:

(a) For the common network points selected as the datum point, the transformation matrix is formulated as

$$
\mathbf{G}_{3, u}=\left[\begin{array}{rrrrrrrrrrr}
\frac{1}{\sqrt{p}} & 0 & 0 & \frac{1}{\sqrt{p}} & 0 & 0 & . & . & \frac{1}{\sqrt{p}} & 0 & 0 \\
0 & \frac{1}{\sqrt{p}} & 0 & 0 & \frac{1}{\sqrt{p}} & 0 & . & . & 0 & \frac{1}{\sqrt{p}} & 0 \\
0 & 0 & \frac{1}{\sqrt{p}} & 0 & 0 & \frac{1}{\sqrt{p}} & . & . & 0 & 0 & \frac{1}{\sqrt{p}}
\end{array}\right]
$$

where $p$ is the number of points in the GPS network. For the partial trace minimum constraints solution, $\mathbf{G}$ matrix is reformed by multiplying $\mathbf{E}_{i}$ matrix. Diagonal elements of $\mathbf{E}_{i}$ matrix are "1" for the datum points and are " 0 " for the others. Thus, under an optimum datum condition, the cofactor matrix for coordinate unknowns is specified (Eshagh, 2009; Küreç, 2010; Küreç and Konak, 2011).

$$
\begin{aligned}
& \mathbf{B}_{i}=\mathbf{E}_{i} \mathbf{G} \\
& \mathbf{Q}_{x x}=\left(\mathbf{A}^{T} \mathbf{P A}\right)^{-}=\left(\mathbf{A}^{T} \mathbf{P} A+\mathbf{B}_{i} \mathbf{B}_{i}^{T}\right)^{-1} \\
& -\mathbf{G}\left(\mathbf{G}^{T} \mathbf{B}_{i} \mathbf{B}_{i}^{T} \mathbf{G}\right)^{-1} \mathbf{G}^{T} .
\end{aligned}
$$


Table 3. A comparison between the sensitivity levels and their orientations in the active block.

\begin{tabular}{|c|c|c|c|c|c|c|c|c|c|c|c|c|}
\hline \multicolumn{5}{|c|}{ 1st solution } & \multicolumn{8}{|c|}{ 2nd solution } \\
\hline Point no. & $\mathrm{dmin}$ & dmax & azimuth & zenith & dmin & dmax & azimuth & zenith & dmin & dmax & azimuth & zenith \\
\hline 101 & 0.47 & 1.33 & 89.890 & 74.894 & 0.28 & 0.85 & 89.849 & 75.816 & 0.28 & 0.83 & 89.839 & 76.745 \\
\hline 102 & 0.66 & 1.86 & 89.932 & 83.857 & 0.49 & 1.43 & 89.958 & 270.243 & 0.49 & 1.44 & 89.958 & 270.906 \\
\hline H22-G001 (103) & 0.99 & 2.75 & 89.983 & 86.822 & 0.81 & 2.29 & 89.978 & 270.243 & 0.81 & 2.29 & 89.974 & 270.527 \\
\hline 34 & 0.50 & 1.42 & 89.998 & 83.746 & 0.34 & 1.01 & 90.034 & 89.732 & 0.34 & 1.03 & 90.048 & 272.114 \\
\hline 35 & 0.52 & 1.43 & 89.984 & 82.548 & 0.37 & 1.03 & 89.992 & 85.274 & 0.38 & 1.06 & 89.998 & 86.048 \\
\hline 36 & 0.53 & 1.45 & 89.974 & 83.544 & 0.38 & 1.05 & 89.972 & 85.578 & 0.39 & 1.07 & 89.977 & 85.572 \\
\hline 37 & 0.55 & 1.49 & 89.947 & 75.038 & 0.40 & 1.07 & 89.918 & 73.178 & 0.40 & 1.09 & 89.922 & 73.195 \\
\hline 38 & 0.58 & 1.53 & 89.961 & 81.545 & 0.38 & 0.96 & 89.943 & 85.026 & 0.39 & 0.97 & 89.948 & 86.238 \\
\hline 53 & 0.40 & 1.15 & 89.977 & 77.553 & 0.33 & 0.97 & 89.992 & 80.716 & 0.33 & 0.96 & 89.988 & 80.585 \\
\hline 55 & 0.56 & 1.49 & 89.937 & 74.801 & 0.49 & 1.28 & 89.932 & 75.421 & 0.49 & 1.29 & 89.933 & 75.954 \\
\hline 56 & 0.67 & 1.76 & 89.922 & 82.980 & 0.58 & 1.52 & 89.900 & 85.060 & 0.59 & 1.55 & 89.904 & 85.495 \\
\hline 57 & 0.64 & 1.66 & 89.948 & 78.032 & 0.56 & 1.43 & 89.941 & 77.322 & 0.58 & 1.47 & 89.943 & 77.543 \\
\hline 58 & 0.60 & 1.72 & 89.983 & 84.356 & 0.50 & 1.47 & 89.992 & 85.864 & 0.51 & 1.50 & 89.995 & 86.230 \\
\hline 66 & 0.52 & 1.45 & 90.037 & 85.400 & 0.47 & 1.33 & 90.061 & 86.346 & 0.47 & 1.33 & 90.062 & 85.774 \\
\hline 67 & 0.47 & 1.27 & 89.938 & 73.179 & 0.42 & 1.13 & 89.941 & 72.643 & 0.42 & 1.14 & 89.943 & 72.577 \\
\hline 70 & 0.38 & 1.13 & 90.016 & 75.296 & 0.32 & 1.00 & 90.039 & 75.001 & 0.32 & 1.00 & 90.042 & 73.722 \\
\hline 71 & 0.41 & 1.14 & 89.952 & 73.721 & 0.36 & 1.00 & 89.957 & 72.782 & 0.36 & 1.00 & 89.959 & 72.450 \\
\hline 72 & 0.46 & 1.33 & 89.933 & 76.428 & 0.39 & 1.14 & 89.921 & 75.673 & 0.40 & 1.16 & 89.918 & 75.644 \\
\hline 77 & 0.34 & 1.03 & 89.972 & 69.785 & 0.29 & 0.90 & 89.975 & 67.912 & 0.28 & 0.90 & 89.976 & 66.371 \\
\hline \multirow[t]{2}{*}{99} & 0.44 & 1.25 & 89.916 & 75.087 & 0.30 & 0.86 & 89.903 & 76.061 & 0.30 & 0.85 & 89.896 & 77.934 \\
\hline & \multicolumn{4}{|c|}{$\frac{\sum d_{\min }}{33}=0.52 \mathrm{~cm}$} & \multicolumn{4}{|c|}{$\frac{\sum d_{\min }}{33}=0.39 \mathrm{~cm}$} & \multicolumn{4}{|c|}{$\frac{\sum d_{\min }}{33}=0.40 \mathrm{~cm}$} \\
\hline
\end{tabular}

(b) A congruence test is realized for 83 common points. As a result of this test, the distributions of moving and fixed points in the network are determined. By also considering the tectonic nature of the region, the active block of the network is defined (Fig. 1). Cofactor elements related to the active block points are selected as a separately sub-matrix from among the cofactor matrix elements. The new cofactor matrix is indicated in the form $\mathbf{Q}_{\dot{x} \dot{x}}$

By using an extended Helmert transformation matrix $(\mathbf{H})$, the cofactor matrix $\left(\mathbf{Q}_{\dot{x} \dot{x}}\right)$ formed for active block points is transformed. Thus, the datum of the active block is identified (Papo, 1999; Even-Tzur, 2006; Küreç and Konak, 2011).

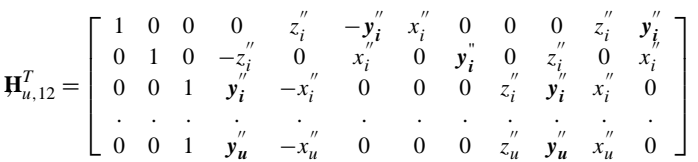

$$
\begin{aligned}
& \mathbf{Q}_{\bar{x} \bar{x}}=\mathbf{H}^{T}\left(\mathbf{H} Q_{\dot{x} \dot{x}}^{-1} \mathbf{H}^{T}\right)^{-1} \mathbf{H}
\end{aligned}
$$


Table 4. Sensitivity and reliability levels of the active block in the Kocaeli GPS-D network.

\begin{tabular}{|c|c|c|c|c|c|c|c|c|c|c|}
\hline \multicolumn{11}{|c|}{ Results of total trace minimum (1st Solution ) } \\
\hline \multirow{2}{*}{$\begin{array}{l}\text { Point } \\
\text { no. }\end{array}$} & \multicolumn{2}{|c|}{$\begin{array}{l}\text { Sensitivities } \\
(\mathrm{cm})\end{array}$} & \multicolumn{3}{|c|}{$\begin{array}{l}\text { Semi-axes of Error } \\
\text { Ellipsoid }(\mathrm{cm})\end{array}$} & \multicolumn{3}{|c|}{ Reliabilities } & \multirow{2}{*}{$\begin{array}{l}\text { Position in network } \\
\text { of points }\end{array}$} & \multirow{2}{*}{$\begin{array}{l}\text { Comment for } \\
\text { sensitivity }(\mathrm{S}) \\
\text { and } \\
\text { reliability }(\mathrm{R})\end{array}$} \\
\hline & $\mathrm{d}_{\min }$ & $d_{\max }$ & $\mathrm{A}_{\mathrm{H}}$ & $\mathrm{B}_{\mathrm{H}}$ & $\mathrm{C}_{\mathrm{H}}$ & $\delta_{\min }$ & $\delta_{\max }$ & $\delta_{\text {mean }}$ & & \\
\hline 101 & 0.47 & 1.33 & 0.91 & 0.32 & 0.47 & 2.20 & 5.42 & 3.23 & An inner zone point & $\mathrm{S}(+)$ and $\mathrm{R}(+)$ \\
\hline 102 & 0.66 & 1.86 & 1.26 & 0.45 & 0.60 & 1.93 & 5.01 & 3.73 & An outer zone point & $\mathbf{S}(*)$ and $\mathbf{R}(+)$ \\
\hline $\begin{array}{l}\text { H22-G001 } \\
\quad(103)\end{array}$ & 0.99 & 2.75 & 1.85 & 0.67 & 0.88 & 1.01 & 11.41 & 3.88 & $\begin{array}{c}\text { An outer zone point } \\
\ell_{103-38}\end{array}$ & $\mathbf{S}(?)$ and $\mathbf{R}(*)$ \\
\hline $\begin{array}{l}\text { H23-G001 } \\
\text { (104) }\end{array}$ & 0.67 & 1.87 & 1.26 & 0.46 & 0.61 & 0.96 & 2.76 & 1.86 & An outer zone point & $\mathbf{S}(*)$ and $\mathbf{R}(+)$ \\
\hline $\begin{array}{l}\text { G22A0002 } \\
\text { (26) }\end{array}$ & 0.52 & 1.42 & 0.96 & 0.35 & 0.44 & 1.31 & 5.79 & 3.62 & Around the NAFZ & \multirow{3}{*}{$\begin{array}{c}\mathbf{S}(+) \\
\text { and } \\
\mathbf{R}(+)\end{array}$} \\
\hline 34 & $\mathbf{0 . 5 0}$ & 1.42 & 0.96 & 0.34 & 0.43 & 1.46 & 5.10 & 2.49 & Around the NAFZ & \\
\hline 35 & 0.52 & 1.43 & 0.97 & $\mathbf{0 . 3 5}$ & 0.45 & 1.81 & 5.79 & 3.49 & Around the NAFZ & \\
\hline 36 & 0.53 & 1.45 & 0.98 & 0.36 & 0.48 & 1.22 & 6.03 & 3.33 & An inner zone point & S (+) and R (+) \\
\hline 37 & 0.55 & 1.49 & 1.01 & 0.37 & 0.52 & 1.31 & 4.52 & 2.63 & Around the NAFZ & S (+) and $\mathbf{R}(+)$ \\
\hline 38 & 0.58 & 1.53 & 1.03 & 0.39 & 0.49 & 1.99 & 11.41 & 5.61 & $\begin{array}{l}\text { A neighbour point to } \\
\text { the outer zone } \\
\ell_{103-38}\end{array}$ & $S(*)$ and $R(+)$ \\
\hline 39 & 0.54 & 1.44 & 0.98 & 0.37 & 0.46 & 1.14 & 10.24 & 3.67 & $\begin{array}{l}\text { A neighbour point to } \\
\text { the outer zone } \ell_{38-39}\end{array}$ & $S(+)$ and $R(+)$ \\
\hline $\begin{array}{c}\text { G23A0003 } \\
(46)\end{array}$ & 0.34 & 1.09 & 0.74 & 0.24 & 0.33 & 1.23 & 5.55 & 2.93 & Around the NAFZ & $S(+)$ \\
\hline $\begin{array}{c}\text { G23A0007 } \\
(47)\end{array}$ & 0.37 & 1.10 & 0.75 & 0.25 & 0.37 & 1.63 & 5.06 & 3.27 & Around the NAFZ & $\mathbf{R}(+)$ \\
\hline $\begin{array}{l}\text { G23-G001 } \\
\quad(48)\end{array}$ & 0.51 & 1.44 & 0.97 & 0.35 & 0.51 & 2.38 & 8.24 & 4.24 & $\begin{array}{c}\text { An inner zone point } \\
\ell_{48-72}\end{array}$ & $\mathrm{~S}(+)$ and $\mathrm{R}(*)$ \\
\hline 53 & 0.40 & 1.15 & 0.80 & 0.28 & 0.36 & 1.92 & 5.55 & 3.74 & Around the NAFZ & S (+) and R (+) \\
\hline 55 & 0.56 & 1.49 & 1.01 & 0.38 & 0.51 & 1.51 & 4.82 & 2.84 & $\begin{array}{l}\text { A neighbour point to } \\
\text { the outer zone }\end{array}$ & $S(+)$ and $R(+)$ \\
\hline 56 & 0.67 & 1.76 & 1.19 & 0.45 & 0.54 & 1.46 & 6.74 & 3.68 & $\begin{array}{l}\text { A neighbour point to } \\
\text { the outer zone }\end{array}$ & $S(*)$ and $R(+)$ \\
\hline 57 & 0.64 & 1.66 & 1.12 & 0.43 & 0.56 & 1.22 & 6.74 & 3.21 & $\begin{array}{l}\text { A neighbour point to } \\
\text { the outer zone }\end{array}$ & $S(*)$ and $R(+)$ \\
\hline 58 & 0.60 & 1.72 & 1.16 & 0.41 & 0.52 & 1.46 & 4.78 & 2.69 & Around the NAFZ & Sensitivity (+) \\
\hline 66 & 0.52 & 1.45 & 0.99 & 0.35 & 0.50 & 0.96 & 4.97 & 2.66 & Around the NAFZ & Reliability (+) \\
\hline 67 & 0.47 & 1.27 & 0.86 & 0.32 & 0.48 & 1.65 & 7.08 & 3.22 & $\begin{array}{l}\text { A neighbour point to } \\
\text { the outer zone }\end{array}$ & $S(+)$ and $R(+)$ \\
\hline 70 & 0.38 & 1.13 & 0.77 & 0.25 & 0.36 & 1.23 & 3.83 & 2.49 & An inner zone point & S (+) and R (+) \\
\hline 71 & 0.41 & 1.14 & 0.77 & 0.28 & 0.40 & 1.87 & 7.08 & 3.58 & Around the NAFZ & S (+) and R (+) \\
\hline 72 & 0.46 & 1.33 & 0.90 & 0.31 & 0.48 & 2.25 & 8.24 & 4.75 & Around the NAFZ & $\mathbf{S}(+)$ and $\mathbf{R}(*)$ \\
\hline 77 & 0.34 & 1.03 & 0.70 & 0.23 & 0.32 & 2.03 & 6.37 & 3.69 & Around the NAFZ & S (+) and R (+) \\
\hline 78 & 0.50 & 1.43 & 0.97 & 0.34 & 0.50 & 2.59 & 6.04 & 3.98 & An inner zone point & S (+) and R (+) \\
\hline $\begin{array}{c}\text { G24A0006 } \\
(83)\end{array}$ & 0.47 & 1.23 & 0.83 & 0.32 & 0.38 & 1.78 & 5.04 & 3.11 & Around the NAFZ & $S(+)$ \\
\hline $\begin{array}{c}\text { G24-G001 } \\
(85)\end{array}$ & 0.42 & 1.20 & 0.83 & 0.29 & 0.38 & 1.74 & 4.51 & 3.24 & Around the NAFZ & $\begin{array}{l}\text { and } \\
\mathbf{R}(+)\end{array}$ \\
\hline 90 & 0.57 & 1.60 & 1.08 & 0.38 & 0.49 & 0.96 & 4.82 & 3.65 & $\begin{array}{l}\text { A neighbour point to } \\
\text { the outer zone }\end{array}$ & $S(*)$ and $R(+)$ \\
\hline 91 & 0.43 & 1.15 & 0.81 & 0.30 & 0.37 & $\mathbf{1 . 5 8}$ & 4.27 & 2.88 & Around the NAFZ & \\
\hline 95 & 0.43 & 1.17 & 0.80 & 0.29 & 0.37 & 1.74 & 5.91 & 3.15 & Around the NAFZ & $S(+)$ \\
\hline 98 & 0.51 & 1.41 & 0.96 & 0.35 & 0.48 & 1.58 & 5.42 & 3.16 & Around the NAFZ & \\
\hline 99 & 0.44 & 1.25 & 0.86 & 0.30 & 0.41 & 2.90 & 5.91 & 4.49 & Around the NAFZ & \\
\hline Degrees of $\mathrm{se}$ & sitivity & & (+): Exce & ent $\left(d_{n}\right.$ & $\leq 0.5)$ & & (*): Suf & cient $(0.5$ & \begin{tabular}{|l|l}
$\left.\mathrm{d}_{\min } \leq 1.0\right)$ & $(?):$ \\
\end{tabular} & Weak $\left(\mathrm{d}_{\min }>1.0\right)$ \\
\hline Degrees of $r$ & ability & & $(+):$ Exc & llent ( & $\leq \delta_{0 i}<$ & & $(*): \mathrm{Su}$ & icient ( & $\left.8 \leq \delta_{0 i}<15\right)$ & Weak $\left(15 \leq \delta_{0 i}<25\right)$ \\
\hline
\end{tabular}




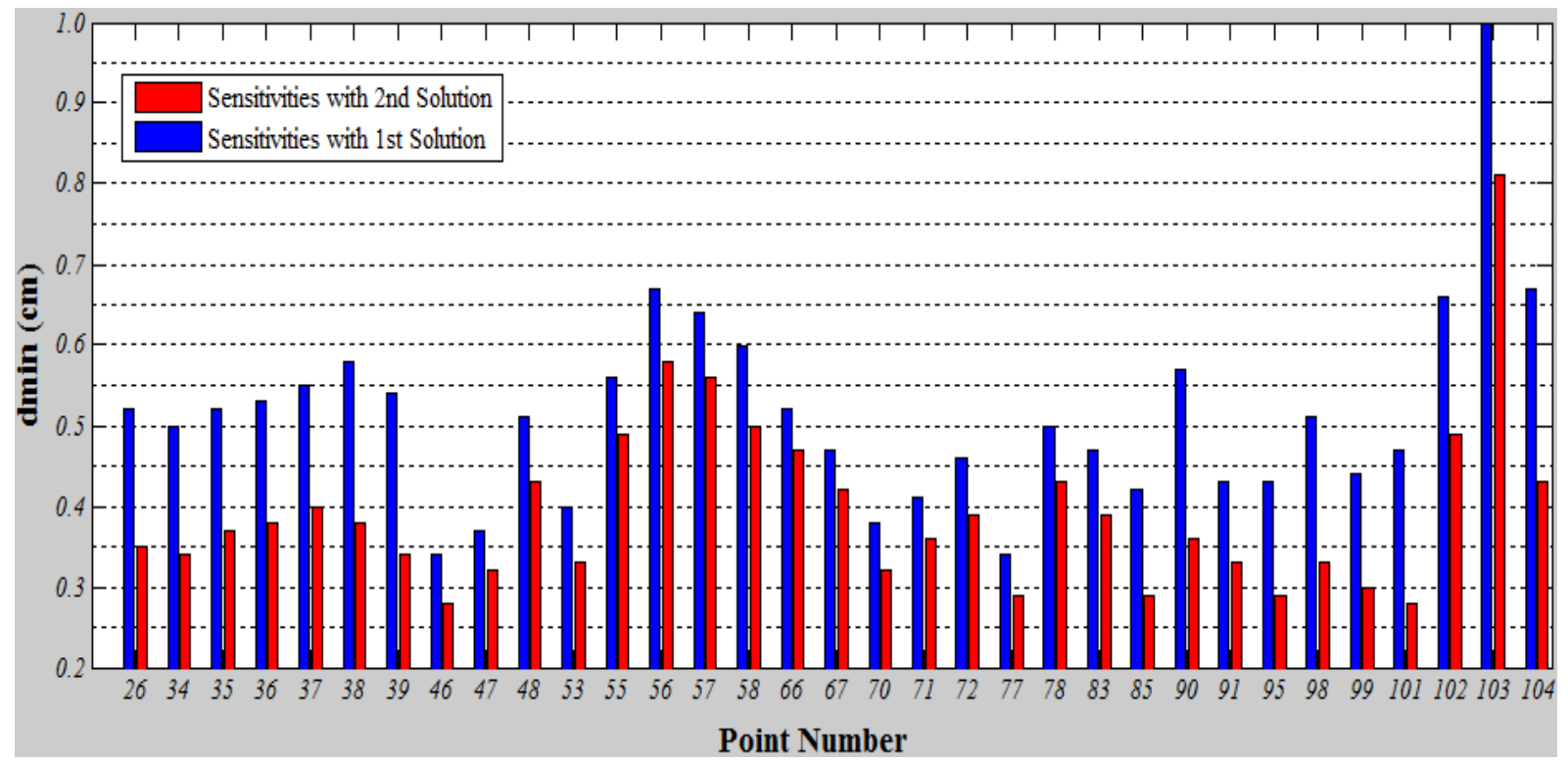

Figure 2. A graphical comparison for sensitivity levels.

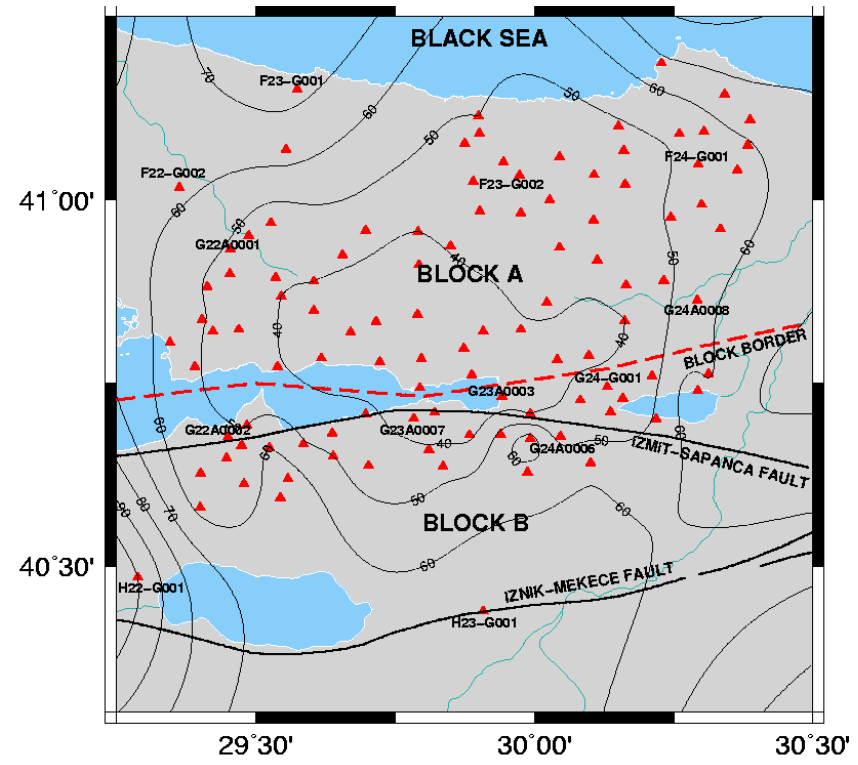

Figure 3. The sensitivity contours map of the Kocaeli GPS-D network (units of contours are $\mathrm{mm} \times 10$ ).

where $\left(x_{i}^{\prime \prime}, y_{i}^{\prime \prime}, z_{i}^{\prime \prime}\right)$ are coordinates whose barycentre is shifted and which standardized; $\mathbf{Q}_{\bar{x} \bar{x}}$ is the cofactor matrix of active block datum.

(c) The weight matrix (N), which is computed for each point in the active block, is decomposed, and their eigenvalues $\left(\lambda_{i}\right)$ and eigenvectors $\boldsymbol{S}_{i}$ ) are computed. The eigenvectors (direction cosines) corresponding to the maximum eigenvalues (principal stress; $\lambda_{\max }$ ) are determined, and then local coordinates of the direction cosines are computed.

(d) Using local coordinates obtained, the azimuth and zenith angles related to the direction cosines are acquired.

(e) According to the zenith and azimuth values, the sensitivity levels are computed (Table 3).

For computations of sensitivity levels, two different solutions are applied:

(a) the total and the partial trace minimum constraint solutions (1st solution)

(b) the total and the partial trace minimum constraint solutions by using extended Helmert transformation for only the active block (2nd solution)

The results are summarized in a table format (Table 3), (Fig. 2).

\section{Analysis and results}

In the both first and second solutions, sensitivity level values do not change according to results of the network evaluations in both the total and partial trace minimum method (Table 3 ). In other words, experimentally, it is observed that sensitivity levels are independent from datum selections. In the first solutions, the sensitivity level values for the whole Kocaeli GPS-D network points vary between 0.34 and $0.99 \mathrm{~cm}$. The mean sensitivity level value is also $0.48 \mathrm{~cm}$ (Fig. 3). 
In the second solution, sensitivity level values decrease (Fig. 2, Table 3). In other words, this case indicates that the extended Helmert transformation improves the minimum detectable displacement capacity of the network.

The best sensitivity level values of the Kocaeli GPS-D network are reached for points closest to the NAFZ. For active block points, the sensitivity level values are between 0.34 and $0.60 \mathrm{~cm}$ for points around the NAFZ, between 0.38 and $0.53 \mathrm{~cm}$ for the inner zone points of the network, between 0.47 and $0.67 \mathrm{~cm}$ for neighbour points to the outer zone of the network and between 0.66 and $0.99 \mathrm{~cm}$ for the outer zone points of the network (Table 3, 4).

Maximum and minimum external reliability values of GPS observations for each single GPS station are computed. These values are between 0.94 and 2.33 for points around the NAFZ, between 1.28 and 2.33 for the inner zone points of the network, between 1.36 and 3.23 for neighbour points to the outer zone of the network and between 0.78 and 3.23 for the outer zone points of the network. Maximum, minimum and mean external reliability values for active block points are illustrated in Table 4.

In Fig. 1, the red base lines show external reliability values higher than 8 . Although they are at the polygonal loops, these observations have a sufficient reliability level. Degrees and decisions of sensitivity and reliability for active block points are illustrated in Table 4.

\section{Conclusions}

Sensitivity and reliability levels are a good indicator for network quality. According to these values, the Kocaeli GPSD network has a sufficiently capacity for the researching of minimum detectable displacement. The mean of sensitivity level is $0.51 \mathrm{~cm}$ for active block. In other words, the Kocaeli GPS-D network is designed sufficiently to sense the annual velocity rates.

If any GPS observation has worse sensitivity $\left(d_{\min }\right)$ or external reliability level $\left(\delta_{\max }\right)$, the weight of this observation and its position in the observation plan must be checked once more. In this case, it should be suggested that a standard SOD is applied.

In this study, the obtained sensitivity and reliability levels are a priori findings for the observation plan at the first epoch. This network should be observed during at least two measurement periods to reach the experimental sensitivity analysis results. According to a priori findings, it is decided that any improvement on the network's observation plan is not necessary.

Finally, the second solution based on extended Helmert transformation gives results more optimistic than the first solution. However, results from the first solution are quite sufficient.
Acknowledgements. This work has been supported by the IZDOGAP project. The authors are greatful to all members of IZDOGAP. Special thanks are due to Cankut D. Ince for grammatical comments. Furthermore, we would like to thank M. Yetkin and four anonymous referees for their very helpful suggestions.

Edited by: S. Tinti

Reviewed by: M. Yetkin and four anonymous referees

\section{References}

Aksoy, A., Ayan, T., Deniz, R., Yalın, D., Karasu, H., Seeger, H., Franke, P., Altıner, Y., Hirsch, O., and Bautsch, P.: Determination of Earth Crust Movements with Spatial Geodetic Techniques in Turkey, Congresses of TUJJB and TUFUAB, Ankara, Turkey, 1995.

Baarda, W.: A Testing Procedure for Use in Geodetic Networks, Publication on Geodesy, Delft, Netherlands, 3, 64-71, 1968.

Berber, M.: Robustness Analysis of Geodetic Networks, University of Brunswick, Canada, 2006.

Boljen, J.: Ausgewählte Kapitel der Landes- und Ingenieurvermessung, Hannover, 193-235, 1993.

Cross, P. A.: Numerical Methods in Network Design, Optimization and Design of Geodetic Network (Ed: Grafarend and Sanso), Part F, Stuttgart and Milano, 132-164, 1985.

Even-Tzur, G.: Datum Definition and its Influence on the Sensitivity of Geodetic Monitoring Networks, 12th FIG Symposium, 4-9, 2006.

Even-Tzur, G.: More on Sensitivity of a Geodetic Monitoring Network, Journal of Applied Geodesy, Germany, 4, 55-59, 2010.

Eshagh, M.: Scalar Risk Functions as Criteria for Datum Definition in Geodetic Networks, Islamic Azad University, Iran, 3-7, 2009.

Han, J. Y., Guo, J., and Zheng, Z. Y.: Sensitivity Analysis for the Principal Strain Parameters of a Deformation Monitoring Network, Journal of Surveying Engineering, Submitted August 21, 2011.

Hsu, R. and Hsiao, K.: Pre-Computing the Sensitivity of a GPS Station for Crustal Deformation Monitoring, Journal of the Chinese Institute of Engineers, 12-15, 2002.

Hsu, R., Lee, H. C., and Kao, S. P.: Statistical Tests for Discerning Differences of Robustness of Horizontal Geodetic Networks due to Different Approaches, Journal of the Chinese Institute of Engineers, Taiwan, 31, 71-80, 2008.

İnce, C. D., Baykal, O., Çakmak, R., Dikbaş, A., Erden, T., Ergintav, S., İpbüker, C., Özşamlı, C., Şahin, M., Tarı, E., Tarı, U., and Tüysüz, O.: GPS Measurements along the North Anatolian Fault Zone on the Mid-Anatolian Segment, Proceedings of International Symposium and Exhibition, Geodetic Photogrammetric and Satellite Technologies-Development and Integrated Application, Sofia, 351-359, 2001.

IZDOGAP: Monitoring of IZGAZ-Natural Gas Infrastructure using National Geodetic Networks and Land Information Systems (IZDOGAP), Technical Reports (Turkish),edietd by: Haluk Konak, A Project of Scientific Research, Kocaeli University, 2011.

Koch, K. R.: Parameterschätzung und Hypothesentests in Linearen Modellen, Bonn, 2004.

Konak, H., Dilaver, A., and Öztürk, E.: Effects of Observation Plan and Precision on the Duration of Outliers Detection and Fuzzy 
Logic: A Real Network Application, Survey Review, UK, October, 298, 331-341, 2005.

Konak, H.: Optimization of the Surface Network, Doctoral Thesis, KTU, Trabzon, 1995.

Kuang, S.: Optimization and Design of Deformation Monitoring Schemes, Technical Report No. 157, University of New Brunswick, 104-106, 1991.

Küreç, P.: Evaluation of the Surface Network, Master Thesis, KOU, Kocaeli, 2010.

Küreç, P. and Konak H.: Precision of Densification Networks Against to Crustal Movements and Possible Sensitivity Levels, hkm Journal of Geodesy, Geoinformation and Land Management, UCTEA, 2011/2, Turkey, 81-87, 2011.

Niemeier, W.: Ausgleichungsrechnung, De Gruyter Lehrbuch, New York, Berlin, ISBN 3-11-014080-2, 2002.
Öztürk, E. and Şerbetçi, M.: Adjustment Computations (Turkish) Vol. 3, Karadeniz Technical University, Publication No. 144/40, Trabzon, 1992.

Papo, H. B.: Datum Accuracy and its Dependence on Network Geometry, International Scientific and Technical Conference, 4-9, 1999.

Pelzer, H.: Zur Analyse Geodätischer Deformationsmessungen, DGK Reihe C 164, München, 1971.

Schmitt, G.: Second Order Design, Optimization and Design of Geodetic Network (Ed.: Grafarend and Sanso), Part D, Stuttgart and Milano, 74-120, 1985.

Wolf, H.: Ausgleichungsrechnung, Formeln zur Praktischen Anwendung, Dümmler Verlag, Dümmlerbuch 7835, Bonn, ISBN 3-427-78351-0, 1975.

Yetkin, M. and İnal, C.: L1 Norm Minimization in GPS Networks, Survey Review, 43, 523-532, 2011. 